\title{
Maman, tu seras là ?
}

\section{Anne de la Brunière et Sarah Dauchy Illustrations de Savine Pied Nane éditions, 2012}

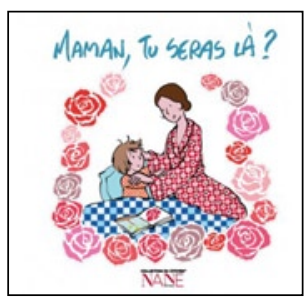

Les ouvrages destinés aux enfants dont un proche est malade sont rares. Celui-ci a le mérite de ne pas se consacrer directement aux enfants de malades, mais de manière implicite à ceux qui sont séparés de leur maman lors d'une hospitalisation.

Les dessins sont très chaleureux, le ton aussi, qui n'hésite pas à employer des mots doux et câlins dans le dialogue de la mère et de sa fille. La petite fille est en effet l'héroïne de ce livre (dans la littérature enfantine, ce sont majoritairement les garçons, les héros), et elle questionne sa mère au sujet de son amour pour elle avant même sa naissance, de l'amour de ses parents et des identifications ressenties confusément encore. Elle veut s'assurer de la présence de sa mère, même lorsqu'elle est absente concrètement, ce qui témoigne d'une inquiétude quant à une potentielle séparation d'avec elle. L'épisode de l'hospitalisation est abordé très légèrement sous la forme d'une colère de l'enfant qui s'exprime par une bouderie à l'égard de ses parents. La mère répond par sa confiance, mais insiste aussi sur l'autonomie de la petite fille, capable de créer, en son absence, des liens avec ses amis et des plats pour les régaler. La mère assure sa fille de son amour passé, présent et à venir, tandis que la fille s'interroge sur ses ressemblances à ses parents et sa place dans sa famille. Elle finit par rêver d'un chemin qu'arpentent ses parents, tandis qu'elle les précède en tenant son cerf-volant, symbole de liberté.
Un joli livre, peu accroché à une histoire, mais plutôt évocateur des sentiments éprouvés à l'égard de ses parents. Le livre est plein d'amour, mais les bémols sont clairement exprimés (le départ de la mère, l'amour des parents qui peut isoler l'enfant, l'ambivalence face à l'autonomie, l'acceptation des ressemblances). L'enfant qui reçoit ce livre peut se l'approprier en y écrivant son nom, il peut jouer à répondre aux propositions identitaires (les garçons peuvent jouer eux aussi) : qui suis-je ? Ce que j'ai de Maman, ce que j'ai de Papa... Plus tard, je serai ? Plus tard, j'habiterai... Plus tard, j'aurai... finalement, ce que je suis moi...

Le vocabulaire est adapté, pas tout à fait interchangeable du côté des sexes, le Papa a un front, des mains, un appétit, une concentration, de longs discours... La Maman a une silhouette, une timidité, des passions, des dons... de la grâce. Tout cela n'est pas très grave, il reste de ce livre une impression de bien-être et de chaleur que tous les enfants aimeraient connaître avec leurs parents. Et, si ce n'est pas le cas, le livre leur transmettra ce bonheur, bien réconfortant lors d'une séparation.

M.-F. Bacqué Rédactrice en chef de Psycho-Oncologie EA 3071, université de Strasbourg, F-67000 Strasbourg, France Correspondance : mfbacque@club-internet.fr 